\title{
Domestic Violence against Women: Higher Tax on Alcohol Could Protect Women
}

\author{
John Simister \\ Manchester Metropolitan University, Manchester, England \\ Email:j.g.simister@mmu.ac.uk
}

Received 26 March 2016; accepted 20 May 2016; published 23 May 2016

Copyright (C) 2016 by author and Scientific Research Publishing Inc.

This work is licensed under the Creative Commons Attribution International License (CC BY). http://creativecommons.org/licenses/by/4.0/

(C) (7) Open Access

\begin{abstract}
Domestic violence against women is a very widespread problem, thought to affect about a third of women worldwide: hence, there may be a billion victims. The consequences of violence within the home can be devastating - often leaving women permanently injured, and sometimes resulting in her death. This paper reports recent evidence on the problem, confirming the link between alcohol consumption and violence. Governments can do more to support women: a new tax on alcohol could pay for services to protect violence.
\end{abstract}

\section{Keywords}

\section{Gender-Based Violence, Alcohol, DHS}

\section{Introduction}

This paper studies physical violence of men against women: focusing on married or cohabiting heterosexual couples, where the husband attacks his partner (whether she is married or not). Various terms are used to describe domestic violence, such as "Intimate Partner Violence"; this paper uses the term "Gender-Based Violence" (GBV) - which implies that many men use violence to control their wife/partner. There are other types of violence within families: such as violence against husbands, and child abuse. Physical violence is not the only problem: there are other forms of violence and control—such as threats, withholding financial support, and sexual violence. All such violence is widely considered unacceptable, but limiting the scope of this paper has advantages. The use of questionnaires to gain information on GBV is also controversial: researchers from a qualitative background may consider that in-depth interviewing is more reliable. Due to the severity and complexity of domestic violence, it is appropriate for many researchers (from different backgrounds) to carry out research.

\section{Literature Review}

This paper investigates Gender-Based Violence. Morrison \& Orlando [1] claim “The adjective 'gender-based' is 
frequently used to highlight the role that women's subordinate status in society plays in increasing the risk that they will be impacted by violence". This paper uses a different view of GBV: that it refers to male use of violence to control his wife/partner. Morrison \& Orlando imply a woman is likely to be a victim of violence because she is subordinate to her husband (subordination causes violence); whereas this paper assumes a women is likely to be subordinate because her husband/partner uses violence (violence causes subordination).

There have been numerous studies of GBV in recent decades; this paper investigates quantitative methods (while acknowledging that qualitative methods are also essential, to improve our understanding). Quantitative research has many uses, such as to identify which countries have the greatest problems-and hence are most in need of funding, to support victims and reduce GBV in future. However, García-Moreno et al. [2] wrote "There were many differences in the way violence was defined, measured and presented. For example, some studies of partner violence include only physical violence, while others may also include sexual or emotional violence [...] Studies also differ in other important respects, such as the definition of the study population (for example, in terms of the age range and partnership status of the women), the forms of violence considered, the range of questions asked, and whether measures were taken to ensure privacy and confidentiality of interviews. Such factors have since been shown to greatly affect prevalence estimates”. To reduce the risk that such differences may give a misleading impression, it may be appropriate for some researchers to limit their analysis to one method of collecting data.

Department of Economic and Social Affairs [3] wrote "In a survey situation, a detailed list of different acts of physical violence (without using the term "violence") is better able to capture physical violence than a general question about physical violence, the interpretation of which is dependent on subjective perceptions". The "Conflict and Tactics Scale" (CTS) is widely used for researching domestic violence (as part of a questionnaire): Alhabib et al. [4] report that CTS is the most widely-used approach, in their analysis of global domestic violence research. A key advantage of this approach is that surveys using CTS are available from many countries.

This paper analyses DHS data on GBV, assuming the questionnaires are close enough to permit comparison between countries. There are slight differences between countries: for example, hair-pulling is included in the list of physical violence in some countries surveyed by DHS, but not others. Another issue is translation of the questionnaire between languages: there seems no way to assess how much this influences results. Readers may be sceptical about comparing data from different surveys, as implied by this quote from some leading researchers: "Although the DHS and IVAWS are internationally comparable, in practice, there are slight methodological variations between the individual surveys, which may limit comparability" [5].

To improve reliability of estimates, it is useful that surveys analysed in this paper are nationwide (including urban and rural locations, and different regions of each country studied). For simplicity, this paper only considers evidence from interviewing women (only a few surveys ask such questions of men). The age-range of women varies to some extent-for example, usually interviewing women age 15 to 49 years in DHS. Some surveys are more recent than others, so a misleading impression could be given if there are rapid changes in GBV prevalence. The experience of GBV in the 12 months before interview may change from year to year, in response to current events; we might expect the lifetime prevalence would change less from one year to the next.

Several writers report that surveys (and other ways to estimate GBV) understate the prevalence of GBV: "because of the sensitivity of the subject, violence against women is almost universally under-reported" [6]. This is a concern, because it may make some politicians complacent about GBV. It may be a good idea for researchers who analyse GBV prevalence to remind readers that the true figures are probably even worse than estimates reported by surveys.

Previous research makes it clear that alcohol causes many problems, including domestic violence [7]. For example, Katikireddi, Bond \& Hilton [8] state "Regular heavy alcohol consumption and binge drinking are associated with physical problems, antisocial behaviour, violence, accidents, suicide, injuries and road traffic crashes". Morrison, Ellsberg \& Bott [9] studied household survey data from nine countries: "Mirroring the results of many other studies, alcohol abuse by the male partner is strongly associated with violence. Women with male partners who "come home drunk frequently" are four to seven times more likely to suffer violence". Similarly, Morrison \& Orlando [1] wrote "Alcohol abuse by the partner significantly raises the probability of violence in the two countries-Peru and Haiti-where this variable is available; in Peru, it increases the probability of violence more than nine times". World Health Organization [10] state "Strong links have been found between alcohol use and the occurrence of intimate partner violence in many countries. Evidence suggests that alcohol use increases the occurrence and severity of domestic violence”; a plausible mechanism is that alcohol affects a 
drinker's cognitive function, reducing his self-control. This paper highlights quantitative evidence; but links between alcohol and GBV have also been confirmed by qualitative researchers, such as O’Brien et al. [11]. GBV and excessive alcohol use also appear to harm children in the same household [12].

To reduce "Violence Against Women and Girls" (VAWG), Action Aid [13] make three recommendations for governments and international agencies: show leadership in combatting GBV; support women's organisations, including their unique role in implementing and holding governments to account on VAWG commitments; and ensuring finance is available to eradicate VAWG."Violence against women and girls is prevalent worldwide but historically has been overlooked and condoned. Growing international recognition of these violations creates opportunities for elimination, although solutions will not be quick or easy. Governments need to address the political, social, and economic structures that subordinate women, and implement national plans and make budget commitments to invest in actions by multiple sectors to prevent and respond to abuse” [14]. Among other interventions, García-Moreno et al. [14] recommend governments "promote the reduction of alcohol use" to reduce GBV.

Some governments support domestic violence victims. For example, the United States government pays for activities of the "Family Violence Prevention and Services Act" (FVPSA): "These funds reach 1505 domestic violence shelters and 1129 nonresidential service sites, providing both a safe haven and an array of supportive services to intervene in and prevent abuse. Each year, FVPSA-funded programs serve 1.3 million survivors and their children and respond to 2.7 million crisis calls” [7]. In 2014, the U.S. government spent over \$89 Million to deal with domestic violence [7], but such expenditure may be difficult for poor countries to afford. An alternative is to use revenue from alcohol taxes, to reduce the problem of GBV—by discouraging excessive alcohol consumption, and by supporting GBV victims.

How can governments reduce GBV? To reduce the harmful effects of alcohol on GBV, it may be appropriate for taxes on alcohol to be increased. One approach is a tax like "Value Added Tax", which could make alcoholic drinks more expensive. But Katikireddi, Bond \& Hilton [8] recommend raising the minimum price of alcohol, to achieve various health improvements; they claim a minimum alcohol price is more effective than general taxes on alcohol, as a way to discourage excessive alcohol consumption. A minimum price can be achieved by a "specific excise tax" on alcohol, rather than using an "ad valorem" tax [7].

There is considerable evidence that taxing alcohol is an effective way to reduce alcohol consumption [15]. Increasing the price of alcohol is generally effective in reducing violence; "in the USA it has been estimated that a $1 \%$ increase in the price of alcohol will decrease the probability of intimate partner violence towards women by about 5\%” [10].

This paper does not advocate a complete ban on alcohol, for various reasons. Moderate drinking can have health benefits, such as reduced blood pressure. If alcohol were made illegal, it would continue to be sold illicitly — but might lead to other problems, such as encouraging organised crime (as associated with USA experience of "prohibition" in 1920s).

\section{Data and Methods}

All data in this paper are from Demographic and Health Surveys (DHS), which have been carried out in numerous low-income countries for decades. DHS is funded largely by USAID; surveys are carried out in cooperation with the government of the country studied. Sampling methods vary to some extent between surveys, but the majority of respondents are women age 15 to 49 years of age (in most countries, DHS also question a smaller sample of men).

DHS use large, nationally-representative, samples of people. Households are selected randomly, using twostage cluster sampling: the first stage selects a list of locations, and the second stage selects districts in these locations. Households are then randomly chosen in the selected districts. In households containing more than one woman, a woman is selected for interview. Interviews were conducted face-to-face by trained interviewers; care is taken to ensure the safety of interviewees (so that women who disclose GBV are not then punished by their spouse). DHS sampling and interviewing methods are explained in [16]. In my opinion, DHS is the best global source of GBV data. In 2014, the author downloaded all DHS surveys that included data on GBV, which were available at the time. Since then, more DHS surveys have become available; and DHS continues to collect data. For this paper, the sample is limited to women (DHS do not usually ask GBV-related questions, when they interview men). Table A1 in the appendix reports the number of women who answered two of the questions on 
GBV, among the surveys analysed for this paper.

The following types of GBV are from the DHS India survey in 2005 [17], and are based on the CTS scale discussed above:

"(Does/did) your (last) husband ever do any of the following things to you:

a) Slap you?

b) Twist your arm or pull your hair?

c) Push you, shake you, or throw something at you?

d) Punch you with his fist or with something that could hurt you?

e) Kick you, drag you or beat you up?

f) Try to choke you or burn you on purpose?

g) Threaten or attack you with a knife, gun, or any other weapon?”

Other DHS surveys analysed in this paper have a similar list of questions, but there are small differences-for example, "pulling hair" is sometimes added as another form of GBV. Figure A1 (in the appendix) shows part of the DHS questionnaire for the Liberia 2007 DHS survey.

To represent information in DHS surveys, countries are arranged on the horizontal axis of each figure in ascending order of GBV prevalence. The exact order of countries is arbitrary: for this paper, GBV prevalence is measured as the average of the fraction of women in each country who were slapped, or were pushed, by her partner (changing this measure of average prevalence would only affect the order in which countries are shown in figures). For this paper, the term "partner" is used to describe a woman's husband or cohabiting partner; the sample includes women in a polygamous marriage. Women in lesbian relationships are excluded from analysis in this paper.

\section{Results}

The following Figures show countries arranged from lower GBV prevalence on the left, to higher prevalence on the right, as discussed in the "Data and methods" section above. Three lines are shown on each Figure, to represent the extent to which the (female) respondent's (male) partner gets drunk.

The three lines in Figure 1 (showing alcohol consumption) tend to be higher on the right than on the left, because countries are arranged in increasing prevalence (the pattern is not linear, because countries are arranged in order of the average of the GBV variables in Figure 1 and Figure 2). The high levels of GBV shown in Figure 1 are unacceptable, and are a reminder to politicians of the need for intervention.

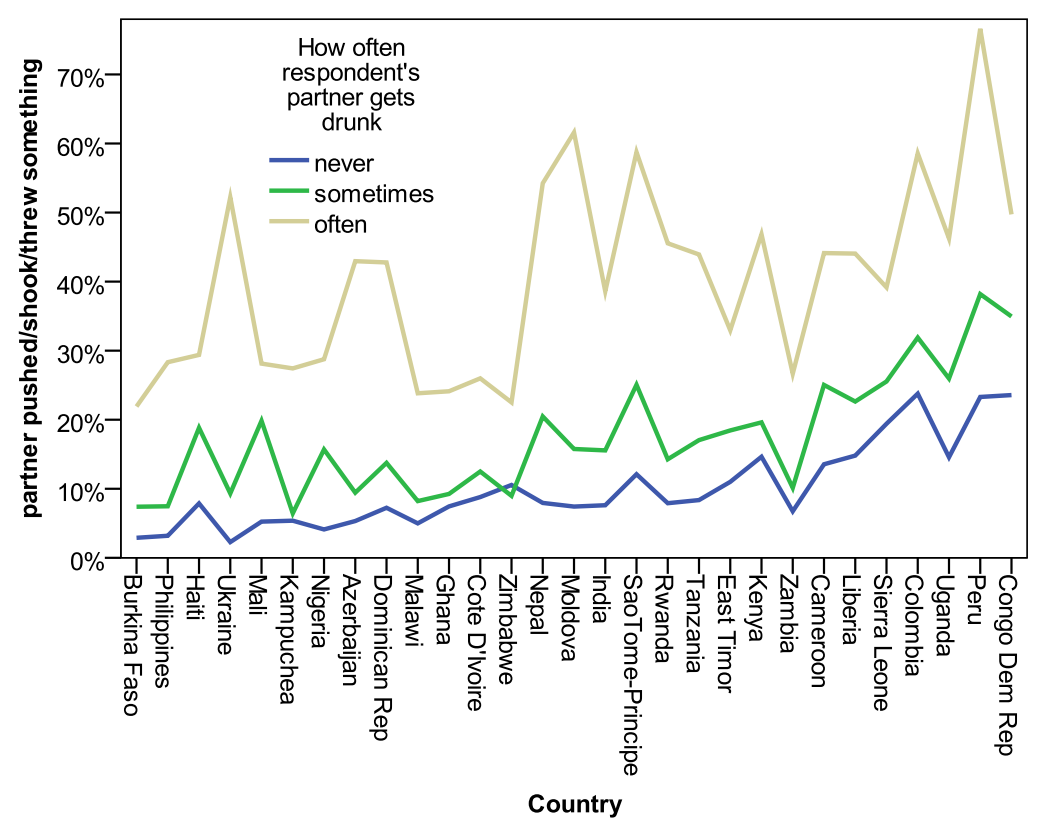

Figure 1. Fraction of women pushed or shaken, or had something thrown at them, by their partner. Source: DHS (author's analysis). 


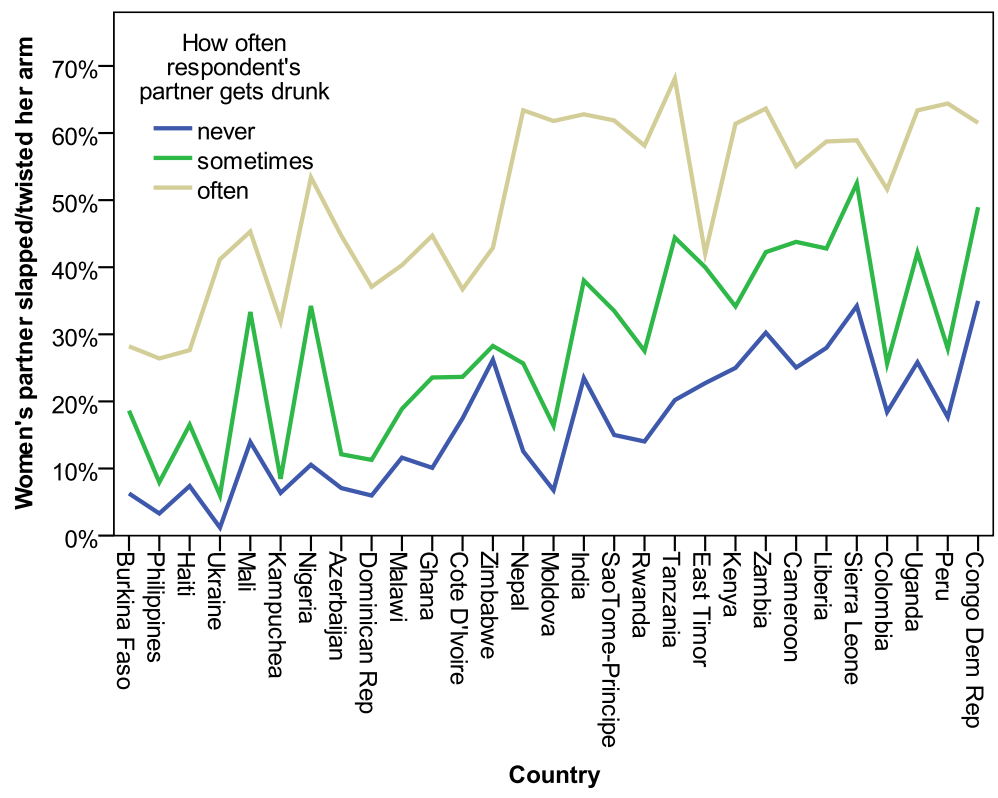

Figure 2. Fraction of women slapped, or had their arm twisted, by their partner. Source: DHS (author's analysis).

A key point of Figure 1 is that where the male partner tends to get drunk "often", there tends to be much more domestic violence: the grey line is much higher than the green and blue lines. The meaning of the terms "drunk" and "often" are interpreted by the female respondent herself, in each DHS survey. Overall, Figure 1 shows strong support for a relationship between excessive alcohol use, and increased GBV risk (as reported by previous research, summarised in the "Literature review" section above).

The horizontal axis of Figure 2 shows countries arranged in the same order as Figure 1, from lower to higher GBV prevalence; hence, there is a tendency for all three lines to be higher on the right than on the left of Figure 2. For this paper, though, the key point is that there tends to be much more domestic violence in homes where the male partner tends to get drunk "often": the grey line (husband gets drunk often) is much higher than the blue line (husband never gets drunk).

Figure 3 indicates a similar pattern to Figure 1 and Figure 2: the key point is that men who "often" get drunk are much more likely to use GBV against their partner. Hence, all three Figures in this paper make clear that excessive alcohol consumption by men is associated with increased risk of women experiencing domestic violence. Reducing alcohol consumption seems likely to reduce the prevalence of violence; hence, it may be appropriate to increases taxes on alcohol.

In a few DHS surveys, respondents were asked if their partner was drunk when he beat them; these responses are shown in Table 1. In the Bolivian and South African surveys, about two-thirds of women report their husband was drunk (or on drugs) when she was beaten by him; but there was a much smaller fraction, 5\%, in Egypt. This difference may reflect Egypt being a mainly Muslim country: drinking alcohol is forbidden by Islam. South Africa is not included in the three Figures above, because detailed CTS questions were not included in the 1998 DHS South Africa survey. The figures of 67\% in Bolivia and 63\% in South Africa in Table 1 can be compared to other research on this topic. According to studies reported in World Health Organization [10], 55\% of GBV victims in USA felt their partner had been drinking prior to a physical assault; the equivalent was $32 \%$ in England \& Wales. Similar links between alcohol and GBV have been found in India, Uganda, Vietnam, and Zimbabwe [10].

Previous research indicates there can be lasting harm to women, as a result of GBV [14]. Some DHS surveys asked if respondents (who had experienced GBV) felt certain types of long-term effects from the violence; results are shown in Table 2. For many women, GBV can lead to long-term fear, anxiety, and suicidal thoughts. In extreme cases, GBV can lead to the victim's death; but such cases are beyond the scope of this paper.

The above evidence confirms that GBV has extremely harmful effects on women, and hence more intervention is needed - from governments, and other organisations such as United Nations agencies. One possibility is 


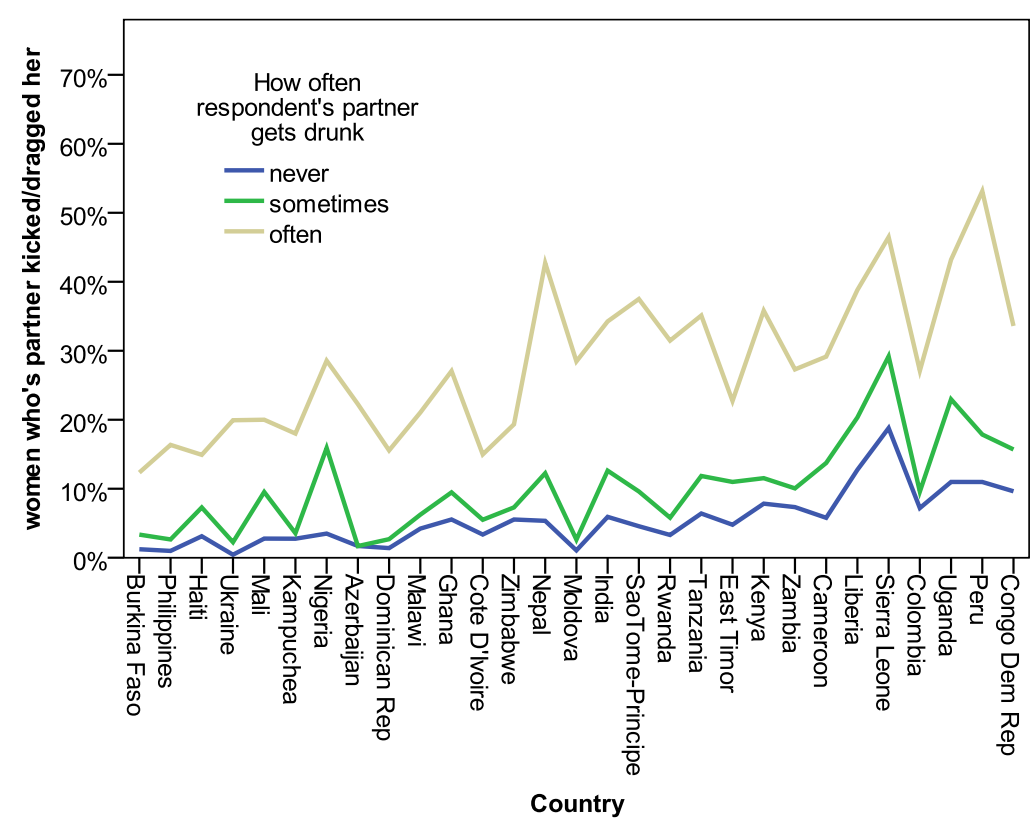

Figure 3. Fraction of women kicked or dragged by their partner. Source: DHS (author's analysis).

Table 1. Extent to which a woman's partner was drunk, when he beat her.

\begin{tabular}{ccccc}
\hline & \multicolumn{2}{c}{ When women was beaten, washer partner drunk/on drugs? } & \multirow{2}{*}{ Number of women interviewed } \\
& no, never & sometimes & frequently or always & \\
\hline Bolivia (2003 \& 2008) & $\mathbf{3 3 \%}$ & $\mathbf{6 7 \%}$ & $\mathbf{3 7 \%}$ & 1589 \\
South Africa (1998) & $\mathbf{3 7 \%}$ & $\mathbf{2 6 \%}$ & $\mathbf{1 \%}$ & 2498 \\
\hline Egypt (1995) & $\mathbf{9 5 \%}$ & $\mathbf{4 \%}$ & & \\
\hline
\end{tabular}

Source: DHS (author’s analysis); sample limited to women who had experienced GBV.

Table 2. Long-term effects of GBV.

\begin{tabular}{ccccc}
\hline & \multicolumn{3}{c}{ Result of physical violence from partner: } & Number of women \\
interviewed & $\begin{array}{c}\text { Constantly fearful of } \\
\text { partner }\end{array}$ & Anxious and depressed & $\begin{array}{c}\text { Thought about committing } \\
\text { suicide }\end{array}$ & 5951 \\
\hline Bolivia (2003 \& 2008) & $\mathbf{6 7 \%}$ & $\mathbf{6 1 \%}$ & & 22,896 \\
Colombia (2005 \& 2010) & & $\mathbf{4 0 \%}$ & $\mathbf{2 3 \%}$ & 2432 \\
\hline Philippines (2008) & & $\mathbf{4 7 \%}$ & $\mathbf{8 \%}$ & \\
\hline
\end{tabular}

Source: DHS (author's analysis): sample limited to women who had experienced GBV.

to discourage (excessive) alcohol use, by increasing taxes on alcoholic drinks. The precise details of how alcohol should be taxed may vary from one country to another.

\section{Conclusions}

This paper adds to the considerable amount of evidence that alcohol consumption by men is a "risk factor" which tends to increase domestic violence against women. The use of DHS data from many countries confirms that this link is not specific to a particular country or culture, but is part of a global pattern. "With increased recognition on how many women's, men's and children's lives are affected by violence, and growing evidence on how to respond to and prevent violence against women and girls, there is no excuse for inaction” [14]. 
This paper advocates raising taxes on alcohol, and using the money to pay for government interventions to reduce the problem of GBV. This could achieve three aims: firstly by making alcohol more expensive, it may reduce the number of men who get drunk and beat their partner. Secondly, by increasing public awareness of the link between alcohol and GBV, it may help women protect themselves from male violence-for example, by leaving home when her husband is drunk. And thirdly, revenue from alcohol taxes can pay for interventions such as advertising the problems of GBV, and funding refuges for battered women. Governments are not the only agencies which can help: for example, medical professionals could tell injured patients about help available for GBV victims, and counselling services for men addicted to alcohol. Schools, colleges and universities could educate students on the problems of excessive drinking, and on the risks of GBV.

Literature reported in this paper shows that alcohol is not the only risk factor relevant to GBV. Researchers, campaigners, activists and governments must continue working hard to reduce GBV prevalence.

\section{Acknowledgements}

The author is grateful to the people and organisations which collected Demographic and Health Survey (DHS) data, and made the data available; analysis in this paper does not necessarily reflect the views of those organisations. Any mistakes in this analysis are the responsibility of the author.

\section{References}

[1] Morrison, A.R. and Orlando, M.B. (2004) The Costs and Impacts of Gender-Based Violence in Developing Countries: Methodological Considerations and New Evidence. World Bank Working paper 36151, Washington DC. http://documents.worldbank.org/curated/en/2004/11/6816749/cost-impacts-gender-based-violence-developing-countrie s-methodological-considerations-new-evidence

[2] García-Moreno, C., Jansen, H.A.F.M., Ellsberg, M., Heise, L. and Watts, C. (2005) WHO Multi-Country Study on Women's Health and Domestic Violence against Women: Initial Results on Prevalence, Health Outcomes and Women's Responses. World Health Organization, Geneva.

[3] Department of Economic and Social Affairs (2014) Guidelines for Producing Statistics on Violence against WomenStatistical Surveys. ST/ESA/STAT/SER.F/110 United Nations, Statistics Division, New York. http://unstats.un.org/unsd/gender/docs/Guidelines_Statistics_VAW.pdf

[4] Alhabib, S., Nur, U. and Jones, R. (2010) Domestic Violence against Women: Systematic Review of Prevalence Studies. Journal of Family Violence, 25, 369-382. http://dx.doi.org/10.1007/s10896-009-9298-4

[5] Devries, K.M., Kishor, S., Johnson, H., Stöckl, H., Bacchus, L.J., Garcia-Moreno, C. and Watts, C. (2010) Intimate Partner Violence during Pregnancy: Analysis of Prevalence Data from 19 Countries. Reproductive Health Matters, 18, 158-170. http://dx.doi.org/10.1016/S0968-8080(10)36533-5

[6] Watts, C. and Zimmerman, C. (2002) Violence against Women: Global Scope and Magnitude. The Lancet, 359, 12321237. http://dx.doi.org/10.1016/S0140-6736(02)08221-1

[7] SAMHSA (Substance Abuse and Mental health Services Administration) (2015) Report to Congress on the Prevention and Reduction of Underage Drinking. PEP14-RTCUAD, Interagency Coordinating Committee on the Prevention of Underage Drinking (ICCPUD), U.S. Government, Rockville, MD. https://www.stopalcoholabuse.gov/media/ReportToCongress/2015/report_main/2015_RTC_Volume_I.pdf

[8] Katikireddi, S.V., Bond, L. and Hilton, S. (2014) Changing Policy Framing as a Deliberate Strategy for Public Health Advocacy: A Qualitative Policy Case Study of Minimum Unit Pricing of Alcohol. The Milbank Quarterly, 92, 250-283. http://dx.doi.org/10.1111/1468-0009.12057

[9] Morrison, A., Ellsberg, M. and Bott, S. (2007) Addressing Gender-Based Violence: A Critical Review of Interventions. World Bank Research Observer, 22, 25-51. http://dx.doi.org/10.1093/wbro/lkm003

[10] World Health Organization (2006) Intimate Partner Violence and Alcohol Fact Sheet www.who.int/entity/violence_injury_prevention/violence/world_report/factsheets/ft_intimate.pdf?ua=1

[11] O’Brien, J.E., Ermentrout, D., Rizo, C.F., Li, W., Macy, R.J. and Dababnah, S. (2015) “I Never Knew Which Way He Would Swing...”: Exploring the Roles of Substances in the Lives of System-Involved Intimate Partner Violence Survivors. Journal of Family Violence, 31, 61-73. http://dx.doi.org/10.1007/s10896-015-9747-1

[12] Klostermann, K.C. and Fals-Stewart, W. (2006) Intimate Partner Violence and Alcohol Use: Exploring the Role of Drinking in Partner Violence and Its Implications for Intervention. Aggression and Violent Behavior, 11, 587-597. http://dx.doi.org/10.1016/j.avb.2005.08.008

[13] ActionAid (2015) Fearless: Standing with Women and Girls to End Violence. ActionAid, London. 
www.actionaid.org.uk/sites/default/files/publications/fearless-standing_with_women_and_girls_to_end_violence_actio naiduk.pdf

[14] García-Moreno, C., Zimmerman, C., Morris-Gehring, A., Heise, L., Amin, A., Abrahams, N., Montoya, O., BhateDeosthali, P., Kilonzo, N. and Watts, C. (2015) Addressing Violence against Women: A Call to Action. The Lancet, 385, 1685-1695. http://dx.doi.org/10.1016/S0140-6736(14)61830-4

[15] Xuan, Z., Chaloupka, F.J., Blanchette, J., Nguyen, T., Heeren, T., Nelson, T.F. and Naimi, T.S. (2015) The Relationship between Alcohol Taxes and Binge Drinking: Evaluating New Tax Measures Incorporating Multiple Tax and Beverage Types. Addiction, 110, 441-450. http://dx.doi.org/10.1111/add.12818

[16] ICF International (2012) Survey Organization Manual for Demographic and Health Surveys. MEASURE DHS, ICF International, Calverton, Maryland. http://dhsprogram.com/Publications/Publication-Search.cfm?type=35

[17] IIPS (International Institute for Population Sciences) and Macro International (2007) National Family Health Survey (NFHS-3), 2005-06: India: Volume II. IIPS, Mumbai. http://dhsprogram.com/publications/publication-FRIND3-DHS-Final-Reports.cfm

[18] LISGIS (Liberia Institute of Statistics and Geo-Information Services) [Liberia], Ministry of Health and Social Welfare [Liberia], National AIDS Control Program [Liberia], and Macro International Inc. (2008) Liberia Demographic and Health Survey 2007. Liberia Institute of Statistics and Geo-Information Services (LISGIS) and Macro International Inc., Monrovia. https://dhsprogram.com/pubs/pdf/FR201/FR201.pdf 


\section{Appendix}

The questions below are part of the DHS Liberia 2007 questionnaire [18], showing the way DHS implement CTS questions on GBV; the questionnaire varies slightly between DHS surveys. Information on how frequently the violence occurred (on the right-hand-side of Figure A1) is not used for this paper.

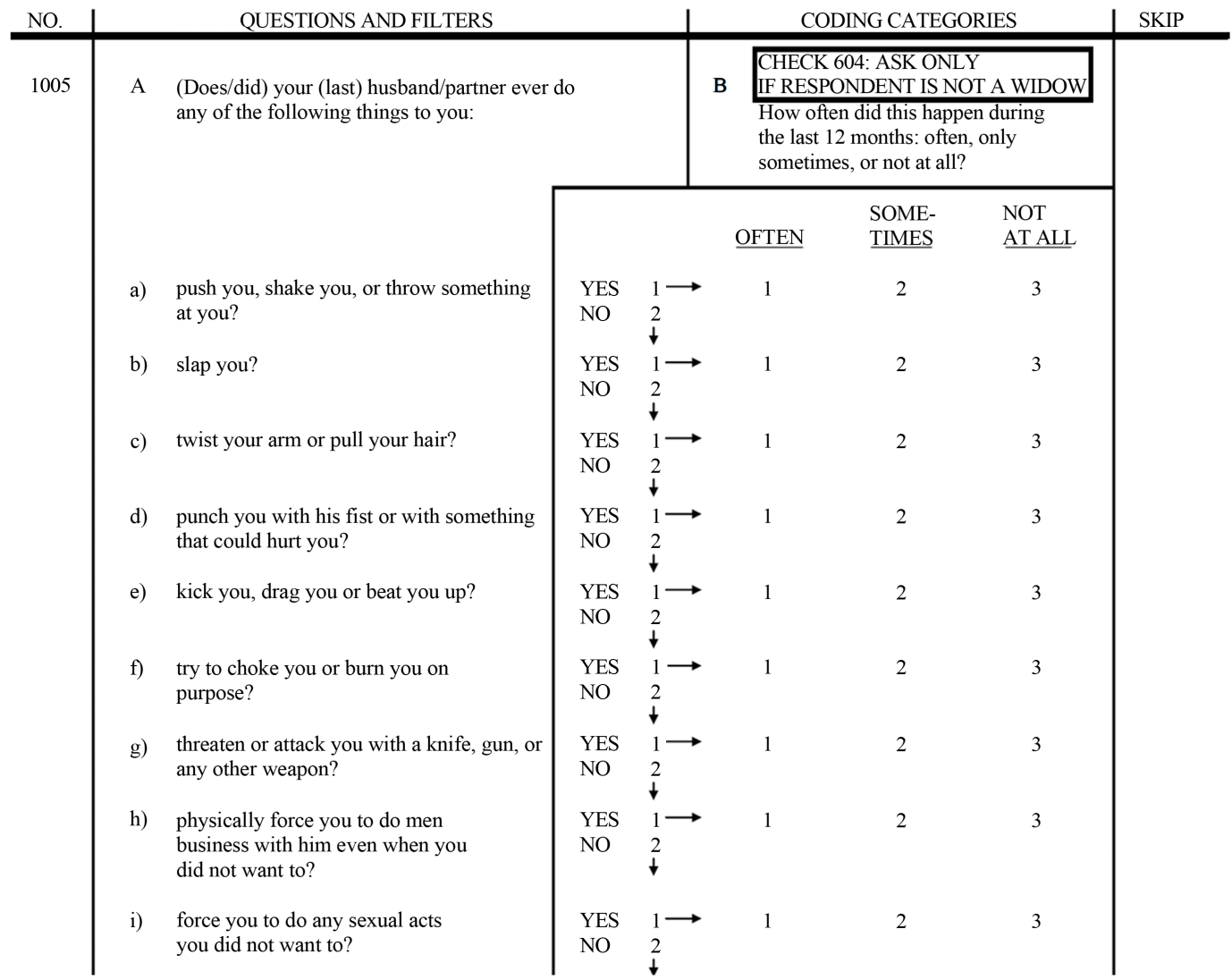

Figure A1. Part of the Liberia 2007 questionnaire referring to GBV questions. Source: [18].

\section{Table A1. Effective sample sizes in DHS surveys.}

\begin{tabular}{cccc}
\hline Country & Year of survey & $\begin{array}{c}\text { Number of women who reported if } \\
\text { their partner pushed/shook her, or } \\
\text { threw something at her }\end{array}$ & $\begin{array}{c}\text { Number of women who reported if their partner } \\
\text { wounded her, or broke her bone or tooth }\end{array}$ \\
\hline Burkina Faso & 2010 & 10,003 & 2431 \\
Philippines & 2008 & 8476 & 469 \\
Haiti & 2000 & 2586 & 298 \\
Ukraine & 2005 & 2676 & 1681 \\
Mali & 2007 & 2417 & 1079 \\
& 2006 & 9035 & 2294 \\
Kampuchea & 2012 & 3120 & 3475 \\
& 2000 & 2401 & 3780 \\
\hline
\end{tabular}




\begin{tabular}{|c|c|c|c|}
\hline Continued & & & \\
\hline Azerbaijan & 2006 & 4299 & 631 \\
\hline & 1999 & 743 & \\
\hline Dominican Republic & 2002 & 7426 & \\
\hline & 2007 & 8421 & 1379 \\
\hline & 2004 & 8291 & \\
\hline MIdidwI & 2010 & 5372 & 1529 \\
\hline Ghana & 2008 & 1835 & 430 \\
\hline Jordan & 2007 & 3444 & 782 \\
\hline Soto D'Juring & 2005 & & 5181 \\
\hline Cote D IVoire & 2011 & 5004 & 1275 \\
\hline 7 imbirs & 2005 & 4960 & 1721 \\
\hline Limivadve & 2010 & 5280 & 1809 \\
\hline Nepal & 2011 & 3505 & 1008 \\
\hline Moldova & 2005 & 4591 & 1019 \\
\hline Nicaragua & 1997 & 8440 & \\
\hline India & 2005 & 69,419 & 22,544 \\
\hline SaoTome-Principe & 2008 & 1729 & 510 \\
\hline & 2005 & 2546 & \\
\hline Kovaria & 2010 & 3468 & \\
\hline Tanzania & 2010 & 5688 & 2068 \\
\hline East Timor & 2009 & 2162 & 757 \\
\hline Egypt & 2005 & 5612 & \\
\hline Kоnй & 2003 & 4312 & \\
\hline & 2008 & 4901 & 1877 \\
\hline Zambia & 2007 & 4226 & 2068 \\
\hline Cameroon & 2004 & 2572 & \\
\hline Liberia & 2007 & 3911 & 1507 \\
\hline Sierra Leone & 2013 & 4308 & 1866 \\
\hline & 2000 & 7716 & 3136 \\
\hline Colombia & 2005 & 25,669 & 10,157 \\
\hline & 2010 & 34,681 & 12,744 \\
\hline Uศวnd & 2006 & 1746 & 984 \\
\hline & 2011 & 1702 & 834 \\
\hline Dory & 2000 & 18,183 & \\
\hline 17ria & 2004-8 & 22,919 & 9504 \\
\hline Congo Dem Rep & 2007 & 2850 & \\
\hline Bangladesh & 2007 & 4467 & \\
\hline Bolivia & 2003 & 14,657 & \\
\hline
\end{tabular}

